\title{
Editorial. \\ El análisis de las imágenes en \\ la era de las fake news
}

\author{
Javier Marzal-Felici \\ Universitat Jaume I \\ Andreu Casero-Ripollés \\ Universitat Jaume I
}

\section{Referencia de este artículo}

Marzal-Felici, Javier y Casero-Ripollés, Andreu (2021). Editorial $n^{\circ} 22$. El análisis de las imágenes en la era de las fake news. En: adComunica. Revista Científica de Estrategias, Tendencias e Innovación en Comunicación, $\mathrm{n}^{0} 22$. Castellón de la Plana: Departamento de Ciencias de la Comunicación de la Universitat Jaume I, 11-20. DOI: http://dx.doi.org/10.6035/2174-0992.2021.22.1

\section{Los medios de comunicación públicos, en crisis permanente}

En estos últimos días, llegan noticias preocupantes sobre Telemadrid, la radiotelevisión pública de la Comunidad de Madrid (RTVM). Es necesario recordar que Telemadrid sufrió en 2012 un ERE muy doloroso, que supuso el despido de 925 trabajadores de los 1.161 empleados que tenía entonces la cadena autonómica. Como sucedió con RTVV, Telemadrid fue objeto durante años de una fuerte campaña de desprestigio, en especial desde 2003, con la llegada de Esperanza Aguirre a la presidencia de la Comunidad de Madrid. A diferencia de lo ocurrido en la Comunidad Valenciana en 2013, al menos el gobierno regional no cerró la radiotelevisión pública, tras las resoluciones contrarias al ERE, tanto del Tribunal Superior de Justicia de la Comunidad de Madrid como del Tribunal Supremo. Sus responsables comprendieron que el cierre de una RTV no una operación fácil, ni carece de graves consecuencias económicas y electorales.

La propia Asamblea de Madrid aprobó una reforma de RTVM en 2015, para nombrar al director/a de la cadena pública, mediante convocatoria pública y mayoría 
parlamentaria. En pocos años, Telemadrid ha ido ganando una reputación positiva entre la ciudadanía madrileña, por su independencia política. El último cambio de ejecutivo ha precipitado en poco tiempo la reforma de la Ley 8/2015 reguladora de la radiotelevisión pública madrileña, que pretende asegurar un férreo control político desde el actual ejecutivo autonómico. Se trata de un golpe autoritario que nos trae a la memoria la fulminante desaparición del Consejo Audiovisual de la Comunidad de Madrid, en 2006, principalmente por no someterse al poder político de turno. Nuestro querido maestro Enrique Bustamante hablaba en 2020 (hace apenas un año) de la existencia de «gobiernos autonómicos gamberros» (Bustamente, 2020) que, sin abandonar una retórica grandilocuente en defensa de las libertades públicas, siguen acorralando a los medios de titularidad pública.

De este modo, el editorial del $n^{0} 22$ de la revista adComunica debe hacerse eco de esta grave crisis en el sistema comunicativo español. Diferentes organizaciones como la Unión Latina de Economía Política de la Información, la Comunicación y la Cultura (ULEPICC-España, 2021), la Asociación de Usuarios de la Comunicación (AUC, 2021) y el Grupo de Estudio Teledetodos (2020) han publicado recientemente diversos manifiestos en los que se denuncian las graves amenazas que están sufriendo los medios públicos españoles, todos ellos con un denominador común: la obsesión de los gobiernos respectivos, principalmente regionales, por controlar a las RTV públicas, y utilizarlos para el control e instrumentalización política. En 2018 (Marzal Felici, 2018), nos referíamos al reiterado cuestionamiento de RTVA, que las fuerzas políticas de derechas consideraban un servicio público prescindible e innecesario. En estos años, se ha ido reduciendo de forma muy significativa el presupuesto de la corporación pública andaluza (Plataforma en Defensa de la RTVA, 2020), lo que ha deteriorado la calidad del servicio público, un hecho que contribuye a dañar su reputación. Se trata de un «modus operandi» habitual en la estrategia de algunas formaciones políticas para desmantelar los servicios públicos.

\section{El reciente anuncio de la creación del Consell de l'Audiovisual de la Comunitat Valenciana: un paso esperanzador}

De forma sorprendente, en la Comunidad Valenciana estamos asistiendo, en estas últimas semanas, a la creación del Consell de l'Audiovisual de la Comunitat Valenciana, un proyecto reaparecido en la agenda de la vida política valenciana, primero con el nombramiento de Empar Marco y de José María Vidal por parte del gobierno valenciano (18/06/2021) y, poco después, con la propuesta de las cinco consejeras/os, por parte de los partidos políticos, que comparecieron en las Cortes Valencianas el pasado 5 de julio (Dolors López, Àlvar Peris, Anna Gimeno, Carmen Carretón y Manuel Alberola, a propuesta de PSPV, Compromís, Unides Podem, Ciudadanos y PP, respectivamente). Todos ellos cumplen los requisitos de la Ley 10/2018, de creación del Consell de l’Audiovisual de la Comunitat Valenciana, en lo 
que respecta al reconocido prestigio y experiencia en el ámbito de la comunicación audiovisual de los/as candidatos/as propuestos/as, por lo que debemos felicitar a las personas designadas y a nuestros representantes políticos por su celeridad y diligencia en la aceleración del proceso.

Desde luego, resulta llamativo el escaso eco recibido en los medios de comunicación, con la excepción de À Punt, y algunas noticias de agencia en pocos medios valencianos. Desde las universidades, tanto en la Comunidad Valenciana, como en el resto del mundo académico español e internacional, la creación del Consell de l'Audiovisual de la Comunitat Valenciana (en adelante, CACV), se valora de forma muy positiva. En primer lugar, constituye un primer paso hacia la normalidad: hay que recordar que el CACV, como autoridad independiente, aparece en el mismo Estatuto de Autonomía de la Comunidad Valenciana. El artículo 81 de la Carta Magna de 1978 recogía la creación del Consejo Estatal de Medios Audiovisuales de España, tema pendiente, por tanto, desde hace más de 40 años. En segundo lugar, el CACV es esencial para el funcionamiento de los órganos de gobierno de los medios de comunicación públicos valencianos, como recoge la Ley 6/2016, tanto porque este órgano ha de proponer el nombramiento de dos personas para el Consejo Rector de la Comunidad Valenciana (CRCV), así como «dictar acuerdos y resoluciones... que afecten a la Corporación o a sus sociedades», además de proponer y seleccionar candidatas/os para la Presidencia de la Corporación Valenciana de la Medios de Comunicación.

Un rápido vistazo al panorama internacional permite tomar conciencia de que, en este campo, nuestro país representa una verdadera anomalía. En todos los países desarrollados existen Consejos Audiovisuales, es decir, organismos independientes, con autoridad para velar por una correcta ordenación y desarrollo de los medios de comunicación. Entre otros, podemos citar:

- La Ofcom, Office of Communications, que nació en 2001, pero sobre la base de cinco organismos reguladores que existían en el país desde la década de los años 30, es el Consejo Audiovisual del Reino Unido.

- El Conseil Supérieur de l'Audiovisuel (CSA), en Francia, fue creado en 1989.

- La Autorità para le Garanzie nelle Comunicazioni (AGCOM) es el órgano regulador en Italia, y se creó en 1990.

- En Alemania existen 14 autoridades reguladoras del audiovisual, los Arbeitsgemeinschaft der Landesmedienanstalten o Consorcio de las Autoridades de los Medios de Comunicación de los Länder, que trabajan de manera coordinada, desde 1998.

- En Bélgica, existe dos Consejos Audiovisuales, uno en Flandes y otro para Wallonia. 
- En Portugal, la Entidade Reguladora para a Comunicação Social se creó en 2004

- Podríamos hablar de otros organismos como la Federal Communications Commission, de Estados Unidos, que nació en 1934 (inicialmente, para regular el espacio de la radiodifusión), pero también de otros organismos como los Consejos Audiovisuales de Australia, Japón, Canadá, Finlandia, México, Chile, etc.

El listado de Reguladores Audiovisuales incluye todos los países de la Unión Europea; algunos de ellos realmente pequeños como Rumanía, Lituania, Eslovenia, Eslovaquia, Malta, Luxemburgo, etc., que disponen de Consejo Audiovisual. En definitiva, es fácilmente constatable que existen Consejos Audiovisuales, es decir, autoridades reguladoras de los espacios comunicativos, en todas partes, incluso en países que son modelo del capitalismo más neoliberal y «desregulado» como Estados Unidos o el propio Reino Unido. La inexistencia de autoridades reguladoras de los espacios públicos de comunicación sería comparable a la ausencia de la Dirección General de tráfico, o del código de seguridad vial para regular el transporte de vehículos en nuestras carreteras. La ausencia de Consejos Audiovisuales tiene que ver directamente con la baja calidad y la escasa competitividad del sector audiovisual y del sistema comunicativo español y valenciano (CECUV, 2015).

Una vez más, creemos necesario recordar que un Consejo Audiovisual no es una entidad creada para «castigar» y «sancionar»: es un órgano que, ante situaciones de conflicto, da instrucciones - cuando se trata de hacer cumplir a operadores o anunciantes el seguimiento de unas normas o códigos-, informa de decisiones - que pueden tener un carácter orientativo para determinadas entidades, empresas o individuos relevantes del sector audiovisual-, hace recomendaciones - que no tienen carácter vinculante- $y$, sí, también pueden dictar sanciones cuando sea necesario - cuando los mecanismos anteriores fallan o cuando se detecta una falta grave de un operador, anunciante o entidad, porque se ha vulnerado la legislación vigente o vulnerado derechos de colectivos sensibles como los niños y jóvenes-. Cabe señalar, contrariamente a lo que se piensa, que no es frecuente los dictámenes de sanciones, porque la misma existencia de este tipo de órganos tiene un efecto disuasorio entre los operadores y agentes del sistema comunicativo y audiovisual del territorio.

Otra función que cabe destacar de los Consejos Audiovisuales es su papel de supervisión y vigilancia sobre la actividad de los operadores, en especial sobre los medios de comunicación de titularidad pública. En este sentido, el CACV contribuirá al cumplimiento de los principios fundacionales de los medios públicos valencianos -la Corporación Valenciana de Medios de Comunicación y su sociedad mercantil, À Punt Mèdia-, en especial su misión de servicio público, su independencia del poder político y de intereses económicos, el uso adecuado del valenciano, la plurali- 
dad informativa, la expresión de la libertad de ideologías, creencias y orientaciones políticas, de la igualdad entre hombres y mujeres, así como favorecer la visibilidad de los colectivos más desfavorecidos o en riesgo de exclusión social, entre otras.

En este sentido, pensamos que el CACV puede contribuir a mejorar, de una manera significativa, la gobernanza o buen gobierno de los medios de comunicación públicos valencianos. También ha de servir para asegurar la participación ciudadana en el gobierno de los medios de comunicación públicos, así como el cumplimiento de los valores que deben sostener este servicio público, que la Unión Europea de Radiodifusión resume en 6 principios, a saber: independencia, universalidad, transparencia, diversidad, excelencia e innovación (EBU, 2012, 2014, 2015 y 2018). El Consejo Audiovisual podría aplicar las pruebas de valor público para garantizar la calidad del servicio público. Y esto pasa por evaluar y, también comunicar al sector profesional y a la sociedad, el impacto social y económico de la comunicación - del periodismo, la comunicación comercial y la oferta de entretenimiento audiovisual-, poniendo por delante la rentabilidad social sobre la económica. Estamos convencidos de que la aparición del Consejo Audiovisual de la Comunidad Valenciana puede contribuir a mejorar la reputación del sector comunicativo y audiovisual valenciano que, a su vez, repercutirá en la propia reputación positiva de nuestro territorio.

Y estamos convencidos de que el Consell de l'Audiovisual de la Comunitat Valenciana puede ser una herramienta muy eficaz para mejorar la investigación en el campo del periodismo, de la publicidad y de la comunicación audiovisual. Si nos fijamos en el trabajo que desarrollan los Consejos Audiovisuales en todo el mundo, veremos como todos disponen de importantes departamentos de investigación, para desarrollar proyectos de innovación, la puesta en marcha de observatorios que ayudan a monitorizar la evolución de la comunicación en el territorio, necesarios para diseñar planes estratégicos para el sector, con beneficios muy claros para el sector privado (no sólo para los medios de comunicación públicos). En este sentido, los CA son aliados naturales para los medios públicos y privados, para fomentar la cooperación y estimular el desarrollo de las empresas que conforman las industrias culturales y creativas del territorio, un sector de alto valor estratégico en todas las sociedades avanzadas.

Y, además, los Consejos Audiovisuales desarrollan una tarea importante en la promoción de la investigación en comunicación, a través de la edición y publicación de estudios e informes, la promoción de colaboraciones entre las diferentes administraciones, especialmente con las universidades y los niveles educativos no universitarios, contribuyendo a la mejora de la competencia mediática de las/os jóvenes y de la ciudadanía en general. 


\title{
El análisis de las imágenes en la era de las fake news
}

Precisamente, este último aspecto conecta directamente con la temática principal de la Sección Informe de este $n^{0} 22$ de la revista adComunica, «El análisis de las imágenes en la era de las fake news». Vivimos rodeados de imágenes, de todos los tipos y clases, en una suerte de una iconosfera que ha convertido a la visión en el órgano sensorial clave de la cultura occidental (Gubern, 1987). La omnipresencia de las imágenes en nuestra cultura ha cambiado nuestra manera de percibir el mundo. Didi-Huberman lo ha expresado así:

\begin{abstract}
«... nunca antes, según parece, la imagen [...] se había impuesto con tanta fuerza en nuestro universo estético, técnico, cotidiano, político, histórico. Nunca antes mostró tantas verdades tan crudas, y sin embargo, nunca antes nos mintió tanto, solicitando nuestra credulidad; nunca antes proliferó tanto y nunca había sufrido tantas censuras y destrucciones» (Didi-Huberman, 2012: 10).
\end{abstract}

En un tiempo marcado por la constante distorsión de la «ảd $\hat{\eta} \theta \varepsilon 1 \alpha »$-aletheia, «verdad», aquello que «se manifiesta claramente tal y como es en su ser»-, tenemos la sensación de haber «perdido la soberanía sobre las imágene» (Fontcuberta, 2016: 260), un objetivo que buena parte de los estudiosos de la comunicación y de la imagen nos empeñamos en recuperar.

Como explicábamos en otro lugar (Marzal-Felici, 2021: 13), en 2017 The Washington Post enunció un provocativo eslogan «Democracy Dies in Darkness» - La democracia muere en la oscuridad- que, en su momento, popularizó el famoso periodista Bob Woodward. En cierto modo, este periódico advertía contra los efectos de la era Trump, que han sido mucho más dramáticos de lo que se esperaba. Es obvio que los medios de comunicación y las redes sociales, amplificadores de los discursos del odio y de las mentiras de Trump y de otros líderes populistas, han sido incapaces de poner coto a los excesos, en gran parte porque se trata de discursos que potencian la "cultura-espectáculo», que una parte importante de la ciudadanía, no sólo «compra» muy bien, sino que además carece de herramientas para identificar la demagogia y la falsedad que se oculta en estos mensajes. Como dice Didi-Huberman,

\footnotetext{
«las imágenes no nos dicen nada, nos mienten o son oscuras como jeroglíficos mientras uno no se tome la molestia de leerlas, es decir, de analizarlas, descomponerlas, remontarlas, interpretarlas, distanciarlas fuera de los 'clichés lingüísticos' que suscitan en tanto 'clichés visuales'» (Didi-Huberman, 2008: 44).
}

En este sentido, el estudio de la cultura visual se revela como una herramienta imprescindible para desenmascarar la manipulación de las masas y para conocer(nos) mejor (Abril, 2007 y 2013). Porque el estudio de las imágenes ofrece una extraordinaria vía para explorar el mundo, abre un amplio horizonte para comprenderlo mejor, y constituye un reto formidable para nuestra inteligencia, dado que, como afirmaba Jameson, «la fuerza transformadora de las tecnologías de la visión ha 
convertido a la imagen en la depositaria de la función epistemológica de nuestro tiempo» (citado por Brea, 2005: 14).

De este modo, coincidimos con los coordinadores del número — con Raúl Rodríguez Ferrándiz y con Teresa Sorolla-Romero-, a quienes agradecemos muy sinceramente su dedicación, cuando afirman que este monográfico pretende promover la reflexión crítica y el debate en torno a una temática muy relevante en estos momentos, en un contexto académico en el que abundan trabajos de corte empírico, y es cada vez menos frecuente la reflexión crítica.

En estos últimos meses, los profesores Ignacio Aguaded, Catedrático de Educación de la Universidad de Huelva, y uno de los autores de este Editorial, Javier Marzal Felici, Catedrático de la Universitat Jaume I de Castellón, hemos impulsado una iniciativa (Marzal-Felici y Aguaded, 2021) a nivel nacional para el desarrollo de la educación mediática en nuestro país, que cuenta con el apoyo de 50 profesores de educación y 50 de comunicación, de 33 universidades españolas. La propuesta trata de dar respuesta a diferentes iniciativas de la Comisión Europea para el desarrollo de las capacidades creativas y críticas de los ciudadanos ante los medios como la Recomendación 2009/625/CE, «Alfabetización mediática en el entorno digital», de la UNESCO, como la Declaración Grünwald (1982), la Declaración de Alejandría (2005) y la Agenda de París (2007), o el European Framework for the Digital Competence of Educators (DigCompEdu) (Comisión Europea, 2017), y el Marco Común de Competencia Digital Docente (INTEF, 2017). En ella se propone la creación de dobles títulos entre los grados de educación y comunicación, así como la actualización de los planes de estudio de estos grados y, muy especialmente, del máster en formación del profesorado, con la introducción de más contenidos relacionados con la educación mediática y con las tecnologías educativas, con el foco puesto en la formación de educadores con altas competencias comunicativas. Una vieja reivindicación que demandan los docentes de todo el sistema educativo no universitario y muchas familias de nuestro país, en especial tras la dura experiencia vivida con el confinamiento y la tele-educación por la pandemia del COVID.

\section{EI inesperado fallecimiento de Enrique Bustamante Ramírez, Presidente de la Asociación Española de Investigación de la Comunicación (AE-IC)}

Desde el pasado 20 de junio han aparecido en periódicos, blogs, sitios web, etc., muchos textos escritos realizados por personas que tuvieron una relación muy estrecha con el recientemente desaparecido Enrique Bustamante, muy querido y apreciado maestro de muchas generaciones de investigadores, docentes y profesionales de nuestro país y de toda Latinoamérica, y un referente intelectual de gran altura internacional. Por citar sólo algunas pocas, muy relevantes, destacan las reflexiones de Miquel de Moragas Spà (2021) o José María Álvarez Monzonci- 
llo (2021). En la sección «Tribuna: Investigación y Profesión», recogemos un perfil extenso que ha preparado el profesor Guillermo Mastrini.

Por nuestra parte, y de forma muy breve, queremos destacar la enorme altura intelectual del profesor Bustamante, sólo comparable con su enorme energía y gran empuje en la defensa firme y crítica de los medios de comunicación públicos y de las industrias culturales, en especial en el contexto latinoamericano.

En un contexto político tan complejo como el actual, al que hay sumar una coyuntura internacional de creciente hegemonía de las grandes plataformas mediáticas, conectadas estrechamente con las multinacionales GAFAM, cada vez más dueñas de nuestros datos y de nuestro imaginario cultural, la aparición en escena del Consell de l'Audiovisual de la Comunitat Valenciana constituye una luz de esperanza, que seguro que habría ilusionado a nuestro estimado maestro Enrique Bustamante.

Pero no debemos ser ingenuos. Como institución de reciente creación, tendrá que pasar por un complejo proceso de aprendizaje, y tiene ante sí retos formidables, a los que no se podrá enfrentar sin el apoyo y trabajo colaborativo de las universidades, de los sectores profesionales valencianos de la comunicación, del periodismo, del audiovisual y de la publicidad, y del conjunto de la sociedad civil valenciana. El éxito del Consejo Audiovisual de la Comunidad Valenciana, sin duda, tendrá un efecto muy directo sobre la calidad de la comunicación. Es responsabilidad de la ciudadanía en su conjunto que este ilusionante proyecto se consolide. Está en juego también la calidad de nuestra joven democracia.

Como ya es habitual, no podemos finalizar nuestro editorial sin dejar de agradecer el compromiso y generosidad de investigadores y profesionales, y del equipo de dirección de la revista adComunica que han participado en este número, de los coordinadores de las secciones y, de nuestra comunidad científica, que contribuyen a fortalecer este proyecto editorial.

\section{Referencias}

Abril, Gonzalo (2007). Análisis crítico de textos audiovisuales. Mirar lo que nos mira. Madrid: Síntesis.

(2013). Cultura visual, de la semiótica a la política. Pozuelo de Alarcón: Madrid Plaza y Valdés.

Álvarez Monzoncillo, José María (2021). «Enrique Bustamante, incansable defensor de los medios públicos de comunicación». El País. Consultado el 15 de julio de 2021 https://elpais.com/television/2021-06-22/enrique-bustamante-incansabledefensor-de-los-medios-publicos-de-comunicacion.html

AUC (2021). «La Asociación de Usuarios de la Comunicación ha manifestado su rechazo a la Proposición de Ley presentada por el Grupo Popular ante el parlamento 
autonómico para modificar la Ley 8/215, de 28 de diciembre, de Radio Televisión Madrid». Teledetodos. Consultado el 15 de julio de 2021 en https://teledetodos. es/index.php/component/k2/item/2849-auc-rechaza-la-contrarreforma-de-radiotelevision-madrid

Brea, José Luis (2005). Los estudios visuales: por una epistemología política de la visualidad. En: Brea, José Luis (ed.). Estudios visuales. La epistemología de la visualidad en la era de la globalización. Madrid: Akal.

Bustamante, Enrique (2020). «Ante el Servicio Público, en plena crisis sanitaria: GOBIERNOS POPULISTAS, POLÍTICOS GAMBERROS». Teledetodos. Consultado el 15 de julio de 2021 en https://teledetodos.es/index.php/component/k2/ item/2728-ante-el-servicio-publico-en-plena-crisis-sanitaria-gobiernos-populistaspoliticos-gamberros

CECUV (Comisión de Expertos en Comunicación de las Universidades Valencianas) (2015). Bases para la renovación del espacio comunicativo valenciano y la restitución del servicio público de radiotelevisión. Valencia: Universidades Valencianas. Consultado el 15/07/2021 en http://hdl.handle.net/10234/179537. Participaron en la redacción del documento: Juan José Bas Portero (Universidad Cardenal Herrera-CEU), Andreu Casero-Ripollés (Universitat Jaume I), Miquel Francés i Domènech (Universitat de València), Josep-Lluís Gómez-Mompart (Universitat de València), José Luis González-Esteban (Universidad Miguel Herández de Elche), Isabel M. Iglesias-García (Universidad Miguel Hernández de Elche), Mar IglesiasGarcía (Universitat d’Alacant), Javier Marzal Felici (Universitat Jaume I), Héctor Julio Pérez López (Universitat Politècnica de València) i Rafael Xambó Olmos (Universitat de València).

Didi-Huberman, Georges (2008). Cuando las imágenes toman posición. El ojo de la historia, 1. Madrid: A. Machado Libros.

Didi-Huberman, Georges (2012). Arde la imagen. Oaxaca: Serieve.

EBU (2012). Empowering Society. A Declaration on the Core Values of Public Service Media. Le Grand-Saconnex: European Broadcasting Union. Consultado el 15 de marzo de 2021 en https://www.ebu.ch/files/live/sites/ebu/files/Publications/ EBU-Empowering-Society_EN.pdf

EBU (2014). Public Service Values. Editorial Principles and Guidelines. Le GranSaconnex,: Media lntelligence Service, European Broadcasting Union. Consultado el 15 de marzo de 2021 en https://www.ebu.ch/publications/position-paper/login_only/guide/public-service-values-editorial

EBU (2015). Public Service Media. Contribution to Society. Le Gran-Saconnex: Media Intelligence Service, European Broadcasting Union, Consultado el 15 de marzo de 2021 en https://www.ebu.ch/contribution-to-society 
EBU (2018). PSM Contribution to Democracy. News, Editorial Standards and Informed Citizenship. Le Grand-Saconnex: Media Intelligence Service, European Broadcasting Union. Consultado el 15 de marzo de 2021 en https://www.ebu.ch/ files/live/sites/ebu/files/Publications/MIS/login_only/c2s/EBU-MIS_PSM-Contribution-to-Democracy_2018.pdf.

Gubern, Román (1987). La mirada opulenta. Exploración de la iconosfera contemporánea. Barcelona: Gustavo Gili.

Marzal-Felici, Javier (2018). ¿Hay que cerrar los medios de comunicación públicos?. Infolibre. Consultado el 15 de julio de 2021 en https://www.infolibre.es/ noticias/opinion/plaza_publica/2018/12/12/hay_que_cerrar_los_medios_comunicacion_publicos_89765_2003.html

Marzal-Felici, Javier (2021). Propuestas para el estudio de las imágenes en la era de la posverdad. En: Profesional de la Información, vol.30, $n^{0} 2$. Barcelona: EPI, e200201. doi: https://doi.org/10.3145/epi.2021.mar.01

Marzal-Felici, Javier y Aguaded, Ignacio (2021). «El Sistema educativo español necesita Maestros expertos en Comunicación». Consultado el 15 de julio de 2021 en https://www.edu-comunicacion.es/tribuna/

Moragas i Spà, Miquel (2021). «Enrique Bustamante, en memoria». Teledetodos. Consultado el 15 de julio de 2021 en https://teledetodos.es/index.php/component/ k2/item/2839-enrique-bustamante-en-memoria-por-miquel-de-moragas

Plataforma en Defensa de la RTVA (2020). «Plataforma en Defensa de la RTVA: Canal Sur de toda y para toda la ciudadanía andaluza». Spandalucia. Consultado el 15 de julio de 2021 en https://www.spandalucia.com/plataforma-en-defensade-la-rtva-canal-sur-de-toda-y-para-toda-la-ciudadania-andaluza/

Teletodos (2021). «AUC rechaza la contrarreforma de Radio Televisión Madrid». Teledetodos. Consultado el 15 de julio de 2021 en https://teledetodos.es/index. $\mathrm{php} /$ component/k2/item/2849-auc-rechaza-la-contrarreforma-de-radio-television-madrid

ULEPICC-España (2021). «Sin concurso público, sin Consejo de Administración, sin reformas. El parlamento y el gobierno degradan el servicio público de RTVE». Consultado el 15 de julio de 2021 en https://teledetodos.es/images/MANIFIESTO_20200928.pdf 